\title{
Within- and between-session CS intensity performance effects in rabbit eyelid conditioning'
} PETHR W. FREY, Northwestern University,
Evanston, Ill. 60201

Eight rabbits were conditioned to blink to a 90-dB tone $(20 \mathrm{~dB}$ above $70-\mathrm{dB}$ white-noise background). After asymptotic performance was apparent, test sessions were given in which high- $(20 \mathrm{~dB})$ and low$(5 \mathrm{~dB})$ intensity tones were used as CSs. Within-and between-day contrasts of the two intensities were compared. Performance was superior with the high-intensity $C S$ in both conditions, but the magnitude of the CS intensity effect was greatest when the two tones were contrasted within the same session.

Animal research has regularly demonstrated a positive correlation between conditioning performance and CS intensity (Razran, 1957; Kamin, 1965; Konorski, 1967). In contrast, the early human conditioning experiments (Carter, 1941; Grant \& Schneider, 1948) reported no effect of CS intensity manipulation and more recent between-S human comparisons have found only small effects (Mattson \& Moore, 1964; Lipkin \& Moore, 1966). Grice and his students (Beck, 1963; Grice \& Hunter, 1964) were the first to demonstrate reliable $\mathrm{CS}$ intensity effects in human conditioning by employing within-S intensity comparisons. The direct contrast of two intensities within a single $S$ appears to markedly enhance differential performance to the two intensities.

The effectiveness of the within-S design has been discussed in terms of adaptation-level theory (Grice \& Hunter, 1964) and response latency models (Grice, 1968). An alternative, although basically similar, interpretation considers the signal detection aspects of this conditioning task. When each $S$ has only a single-intensity $C S$, his response criterion can be adjusted to maximize his performance to that particular CS. For example, for a low-intensity CS, a lax criterion can be employed to increase response probability to the CS. However, when the $S$ is presented with more than one intensity within a single conditioning session, a single response criterion must be adopted which is appropriate for both CSs. Any criterion that is adopted, which insures

Fig. 1. Conditioned response frequency during test sessions as a function of the increase in intensity of the CS above the 70-dB white-noise background. a reasonable response level to the low-jntensity CS, must necessarily result in an increase of the response probability to the high-intensity CS. Thus the enhancement of differential performance in the within-S design can be considered to reflect the necessity of adopting a single response criterion for both $\mathrm{CSs}$. In the between-S design, each group can adopt different criteria for each CS intensity, resulting in more similar performance to the different intensity CSs.

This interpretation of the within-S design effect implies that the observed enhancement of differential performance to the two different CS intensities (1) is primarily related to performance factors rather than to learning factors, and (2) can be attributed to the S's uncertainty within a session concerning which intensity CS will occur on a given trial. The difference between a within- vs between-session contrast of intensities is emphasized rather than the difference between a within-vs between-S contrast of intensities. The present experiment was designed to investigate this interpretation by assessing performance effects dependent upon within- and between-session comparison of different CS intensities within a single group of Ss.

Eight New Zealand white rabbits, weighing 4 to $5 \frac{1}{2} \mathrm{lbs}$ were conditioned. The animals were caged individually and had free access to food and water. The rabbit conditioning equipment has been described previously (Frey \& Ross, 1967, in press). Essentially, each $S$ was restrained in a stock and placed in a sound-attenuated chamber where eyelid movements were recorded graphically using a counter-weighted microtorque potentiometer which was attached to the animal's skull. Two stainless steel wire electrodes, which had previously been sutured just below and to either side of the right eye during the preliminary surgical preparation, were used for presentation of the shock US. The $1000-\mathrm{Hz}$ tone CSs were $5 \mathrm{~dB}$ and $20 \mathrm{~dB}$ above a constant background white noise of $70 \mathrm{~dB}$ (SPL) as measured at the level of S's ears. The US was a 200 -msec constant amperage $(3.5 \mathrm{~mA})$ electric ac shock.

The third day after surgical preparation, each animal was habituated to the stock and conditioning equipment. Training began the day after habituation, with each animal receiving 100 conditioning trials per day for several sessions until a stable asymptotic level of performance was attained (four to six sessions). In this acquisition phase, a $1000 \mathrm{~Hz}$ tone $\mathrm{CS}$ was employed which was $20 \mathrm{~dB}$ above the 70-dB background white noise. This tone was later used as the "high" intensity CS in the test sessions which followed. In acquisition and in subsequent training, a delayed conditioning procedure was used with a 500-msec CS-US interval and $a$ fixed 60 -sec intertrial interval.

After each animal's performance had stabilized with the 20-dB CS, CS intensity performance effects were studied under the following training sequence with 100 trials/session: one session in which 5-dB and 20-dB CSs were alternated, three sessions with the 5-dB CS only, three sessions with the 20-dB CS only, four sessions in which the 5-dB and 20-dB tones were again alternated, and a final session in which the $5-\mathrm{dB}$ and $20-\mathrm{dB}$ CSs were presented in 25 -trial blocks, e.g., 25 trials at $20 \mathrm{~dB}, 25$

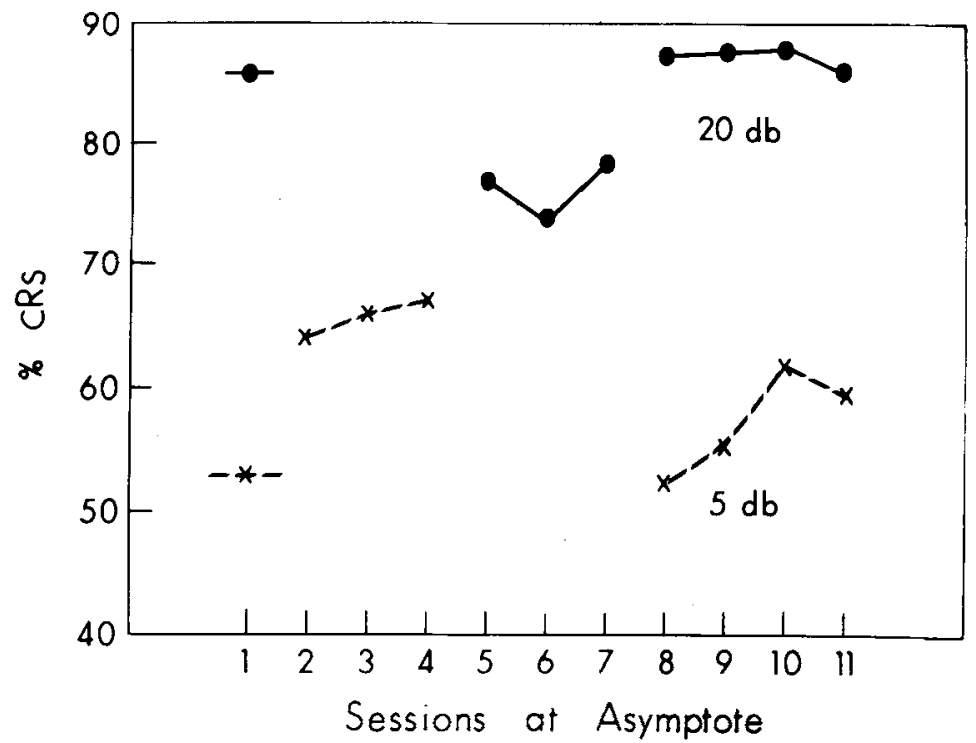

Psychon. Sci., 1969, Vol. 17 (1) 


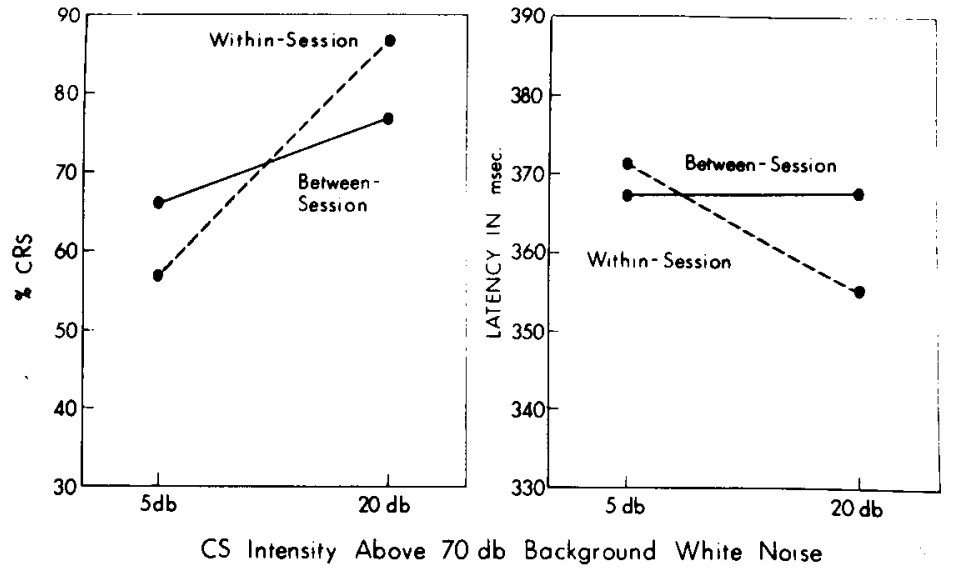

trials at $5 \mathrm{~dB}, 25$ trials at $20 \mathrm{~dB}, 25$ trials at $5 \mathrm{~dB}$. Since research by Leonard \& Theios (1967) and unpublished data from our lab have suggested that rabbits in the eyelid conditioning situation fail to show single alternation discriminatory behavior, the use of alternating 5-dB and 20-dB CS trials provided the maximum possible intermixing of the two intensities while apparently avoiding the cue-schedule discrimination problems commonly associated with altemation sequences.

\section{RESULTS}

The dependent variables studied in the present study were the presence or absence of $\mathbf{C R}$ on each trial, an eyelid closure producing a $2-\mathrm{mm}$, or greater, deflection of the recording pen between CS onset and US onset, and the response latency (in milliseconds) on trials when a CR occurred. On the last day of the initial acquisition training, the eight animals were responding at an average level of $78.2 \%$. The effects of CS intensity manipulation on subsequent days on the rabbit's asymptotic performance are indicated in the response frequency data presented in Fig. 1. Both the within-session contrast of $\mathrm{CS}$ in tensity (Test Sessions 1, 8-11) and between-session contrast (Test Sessions 2-7) indicated higher performance level with the higher intensity CS $[F(1,7)=67.5, p<.001]$. A significant interaction between $\mathrm{CS}$ intensity and the within- vs between-session comparison $[F(1,7)=10.5, p<.02]$ indicated that this $\mathrm{CS}$ intensity effect is enhanced when the two intensities are contrasted within a single session. A subsequent analysis of the CS intensity effect in the between-session comparison demonstrated the reliability of this difference $[t(7)=3.44, p<.02]$.

The mean performance levels over the 11 test sessions are presented for the frequency and latency measures in Fig. 2. The mean values for the frequency data merely summarize the results presented in Fig. 1. The only reliable difference in the latency data is the shorter latency with the high-intensity $\mathrm{CS}$ in the within-session comparisons $[t(7)=2.36, p<.05]$. In summary, these data indicate a small, but reliable enhancement of performance with increased CS intensity in a between-session contrast and a much larger enhancement of performance when a high-intensity $C S$ is contrasted with a lower-intensity CS within a single session. Response latency is shorter to the high-intensity CS only with a within-session contrast of the two intensities.

A further evaluation of the effect of immediate contrast of two different intensity CSs was attempted on Test Session 12 by alternating series of 25 trials in which only one intensity was presented. The response frequency on the first five and last five trials of each of these series was analyzed. The response frequency to the lower intensity CS was $67 \%$ following previous low-intensity CS trials and $57 \%$ following high-intensity CS trials. The response frequency to the high-in tensity CS was $90 \%$ following previous low-intensity CS trials and $77 \%$ following high-intensity CS trials. Statistical analysis of these data indicated that response probability with either CS was reliably higher after previous trials with the lower intensity CS $[\mathrm{t}(7)=2.54, \mathrm{p}<.05]$.

These data are consistent in demonstrating that conditioning performance with the rabbit eyelid response changes as a function of CS intensity and that these changes appear to be related to the intensity of prior CSs within the conditioning session. It is noteworthy that the two CS intensities employed in the present experiment, which differed by only $15 \mathrm{~dB}$ in intensity, produced performance differences almost as large as those observed by Grice \& Hunter (1964) in humans with CSs differing by $50 \mathrm{~dB}$ in intensity. On the basis of the present data, it would appear that the effects reported by Grice \& Hunter (1964) might more accurately be attributed to the within-session contrast of two CS intensities rather than to the special
Fig. 2. Mean conditioned response frequency and latency during the test sessions to the 5-dB and 20-dB CSs, comparing within- vs between-session contrast of the two intensities.

characteristics of within-S as opposed to a between-S design which they emphasized. That is, the size of the CS intensity effect depends upon having both intensities within a single session rather than having both intensities sampled by a single $S$. When the same $S$ has both intensities, but only one of them during any one session, the magnitude of the CS intensity effect is drastically reduced.

\section{REFERENCES}

BECK, S. B. Eyelid conditioning as a function of CS intensity, UCS intensity, manifest anxiety scale score. Joumal of Experimental Psychology, 1963, 66, 429-438.

CAR TER, L. F. Intensity of conditioned stimulus and rate of conditioning. Journal of Experimental Psychology, 1941, 28, 481-490. FREY, P. W., \& ROSS, L. E. Differential conditioning of the rabbit's eyelid response with an examination of Pavlov's induction hypothesis. Journal of Comparative \& Physiological Psychology, 1967, 64, 277-283.

FREY, P. W., \& ROSS, L. E. Rabbit cyelid conditioning as a function of age, interstimulus interval, and intertrial interval. Developmental Psychobiology, in press.

GRANT, D. A., \& SCHNEIDER, D. E. Intensity of the conditioned stimulus and the strength of conditioning: I. The conditioned eyelid response to light. Journal of Experimental Psychology, 1948, 38, 690-696.

GRICE, R. G. Stimulus intensity and response evocation. Psychological Review, 1968, 75, 359-373.

GRICE, G. R., \& HUNTER, J. J. Stimulus intensity effects depend upon the type of experimental design. Psychological Review, 1964, 71, 247-256.

KAMIN, L. J. Temporal and intensity characteristics of the conditioned stimulus. In W. F. Prokasy (Ed.), Classical conditioning: $A$ s y $m$ pos $i$ i $m$. N e w Y or k: Appleton-Century-Crofts, 1965. Pp. 118-147.

KONORSKI, J. Integrative activity of the brain. Chicago: University of Chicago Press, 1967. Pp. 290-291.

LEONARD, D. W., \& THEIOS, J. Classical eyelid conditioning in rabbits under prolonged single alternation conditions of reinforcement. Journal of Comparative \& Physiological Psychology, 1967, 64, 273-276.

LIPKIN, S. G., \& MOORE, J. W. Eyelid trace conditioning, CS intensity, CS-UCS interval, and a correction of "spontaneous" blinking. Journal of Experimental Psychology, 1966, 72, 216-220.

MATTSON, M., \& MOORE, J. W. Intertrial responding and $C S$ intensity $i$ : classical cyelid conditioning. Journal of Experimental Psychology, 1964, 68, 396-401.

RAZRAN, G. The dominance-contiguity theory of the acquisition of classical conditioning. Psychological Bulletin, 1957, 54, 1-46. NOTE

1. This research was supported in part by the Graduate Research Committce of Northwestern University. Reprint requests should be sent to Peter W. Frcy, Department of Psychology, Nor thwestern University, Evanston, Ill. 60201. 